\title{
Twelve-month outcomes of transapical transcatheter aortic valve implantation in patients with severe aortic valve stenosis
}

\author{
Łukasz Wiewiórka ${ }^{1}$, Robert Sobczyński ${ }^{2}$, Jarosław Trębacz ${ }^{1}$, Jerzy Sadowski ${ }^{3}$, Dariusz Dudek ${ }^{4}$, Maciej Stąpór ${ }^{1,5}$, \\ Janusz Konstanty-Kalandyk ${ }^{3}$, Robert Musiał ${ }^{6}$, Andrzej Gackowski ${ }^{5,7}$, Krzystof Malinowski ${ }^{8}$, Paweł Kleczyński ${ }^{9}$, \\ Krzysztof Żmudka9 , Bogusław Kapelak ${ }^{3}$, Jacek Legutko ${ }^{9}$
}

${ }^{1}$ Department of Interventional Cardiology, John Paul II Hospital, Krakow, Poland

2Department of Cardiac Surgery and Transplantation, John Paul II Hospital, Krakow, Poland

${ }^{3}$ Jagiellonian University Medical College, Institute of Cardiology, Department of Cardiac Surgery and Transplantation, John Paul II Hospital, Krakow, Poland

${ }^{4}$ Jagiellonian University Medical College, Institute of Cardiology, Krakow, Poland

${ }^{5}$ Nonivasive Cardiovascular Laboratory, John Paul II Hospital, Krakow, Poland

${ }^{6}$ Department of Anaesthesiology and Intensive Therapy, John Paul II Hospital, Krakow, Poland

${ }^{7}$ Jagiellonian University Medical College, Institute of Cardiology, Department of Coronary Artery Disease and Heart Failure, John Paul II Hospital, Krakow, Poland

${ }^{8} 2^{\text {nd }}$ Department of Cardiology, Jagiellonian University Medical College, Krakow, Poland

'9agiellonian University Medical College, Institute of Cardiology, Department of Interventional Cardiology, John Paul II Hospital, Krakow, Poland

Adv Interv Cardiol 2021; 17, 1 (63): 68-74

DOI: https://doi.org/10.5114/aic.2021.104771

\begin{abstract}
A bstract
Introduction: Transapical access (TA) transcatheter aortic valve implantation (TAVI) (TA-TAVI) represents one of the possible routes in patients with severe aortic stenosis (AS) who are not suitable for transfemoral access.

Aim: To assess early- and mid-term clinical outcomes after TA-TAVI.

Material and methods: Patients with severe symptomatic AS undergoing TA-TAVI from November 2008 to December 2019 were enrolled. Clinical and procedural characteristics as well as clinical outcomes including all-cause mortality during 12-month follow-up were assessed.

Results: Sixty-one consecutive patients underwent TA-TAVI for native AS. Patients were elderly with median age of 80.0 (76.084.0) years; 55.7\% were males. Median baseline EuroSCORE I and STS scores were 18.2\% (11.6-27.7) and 4.8\% (3.3-8.2), respectively. The procedural success rate was $96.7 \%$. In-hospital, 30-day and 12 -month mortality rates were $9.8 \%$; $18.0 \%$ and $24.6 \%$, respectively. The main periprocedural and in-hospital complications were bleeding complications (14.8\%). The following factors were associated with 12-month mortality: previous cerebrovascular event (CVE), glomerular filtration rate (GFR), aortic valve area (AVA), right ventricular systolic pressure (RVSP) and serum level of N-terminal prohormone of brain natriuretic peptide (NT-proBNP) (RR for CVE 3.17, 95\% confidence interval (CI): 1.15-8.76: $p=0.026$; RR for AVA per $0.1 \mathrm{~cm}^{2} 1.28,95 \% \mathrm{Cl}: 1.03-1.55: p=0.024$; RR for GFR per $1 \mathrm{ml} / \mathrm{min}$ 0.96: 95\% Cl: 0.94-0.99: $p=0.007$; RR for NT-proBNP per $1000 \mathrm{pg} / \mathrm{ml} 1.07: 95 \% \mathrm{Cl}: 1.01-1.17: p=0.033$; RR for RVSP per $1 \mathrm{~mm} \mathrm{Hg}$ 1.07: 95\% Cl 1.02-1.16: $p=0.011$ ).
\end{abstract}

Conclusions: Transapical TAVI in high-risk patients provides good hemodynamic results with acceptable outcomes.

Key words: aortic stenosis, high-risk patients, outcomes, transcatheter aortic valve implantation, transapical.

S u m m a ry

Transapical transcatheter aortic valve implantation in patients who are not suitable for a transfemoral approach gives a good hemodynamic result with significant clinical improvement. History of cerebrovascular event, impaired renal function, aortic valve area, increased NT-proBNP and right ventricular systolic pressure level may be associated with higher mortality at the 12-month follow-up.

\section{Corresponding author:}

Łukasz Wiewiórka MD, Department of Interventional Cardiology, John Paul II Hospital, 31-202 Krakow, Poland, e-mail: drlucwie@gmail.com Received: 15.11.2020, accepted: 13.02.2021. 


\section{Introduction}

Aortic valve stenosis (AS) is the most common valvular disease, the frequency of which significantly increases with age. In patients older than 75 years, the incidence of $3.4 \%$ for severe AS represents a serious healthcare issue in Europe and in the United States [1-3]. For many years, a surgical valve replacement was the only effective method for AS treatment. Therefore, high risk surgery patients were very often left untreated and scheduled for pharmacological treatment [4]. Since the first endovascular implantation in 2002, transcatheter aortic valve implantation (TAVI) has become a valuable method for non-operable patients and an alternative to conventional surgical replacement [2]. During wider implementation of transcatheter heart valves, several approaches for TAVI were introduced. The transfemoral approach (TF) is the most common access route associated with the most favorable clinical outcomes [2, 5]. Patients undergoing TAVI constitute a very frail population with multiple comorbidities [6]. Computed tomography for access site evaluation often reveals diffuse severe atherosclerosis with massive calcifications and tortuosity in the iliofemoral region, which is a contraindication for femoral access. Transapical access (TA) represents one of the possible routes in patients who are not suitable for TF access. However, due to more aggressive intervention compared to the TF route and the need for general anesthesia as well as the higher risk profile of patients treated with TA, the apical approach is not often used nowadays and therefore many questions remain about the safety and clinical outcomes $[7,8]$.

\section{Aim}

The aim of our study was to assess early- and midterm clinical outcomes after TA-TAVI in patients with severe AS.

\section{Material and methods}

A total of 61 consecutive high-risk elderly patients with severe symptomatic AS undergoing TA-TAVI from November 2008 to December 2019 were enrolled. Patient screening and selection were performed by a multidisciplinary Heart Team supported by clinical and imaging data. The clinical decision was based on logistic EuroSCORE I and the Society of Thoracic Surgeons (STS) Score [9]. Clinical assessment also included porcelain aorta, advanced liver cirrhosis, severe neurological impairment and frailty status. All procedures were performed by a cardiac surgeon and interventional cardiologist. All procedures were performed under general anesthesia and using Edwards Sapien, XT and Sapien 3 (Edwards Lifesciences, Irvine, USA) and ACURATE neo (Boston Scientific, Marlborough, USA).
After starting a TAVI program in our center, the number of all procedures annually was relatively low, starting from 30-40. Moreover, the TA route was a predominant access for TAVI, at least during the first year due to factors related to patient characteristics, including extremely high risk patients with multilevel atherosclerosis. Afterwards, TF access was gaining in frequency and we ended up with 120 procedures a year, $95 \%$ of which were performed via the TF approach. The number of TA procedures a year was highest between 2008 and 2014, reaching even 16 procedures a year, and since 2015 the number has dropped to 3-5 TA-TAVIs a year.

Baseline characteristics, procedural and outcomes data were collected. Endpoints of the study included allcause mortality at discharge, 30 days and 12 months. Other endpoints were assessed according to the recommendations of the Valve Academic Consortium (VARC) [10]. The study protocol was approved by the institutional ethical board.

\section{Statistical analysis}

Categorical variables were presented as counts and percentages. Continuous variables were expressed as mean (standard deviation (SD)) or median (interquartile range (IQR)), where applicable. Normality was assessed via the Shapiro-Wilk test. Lifetime data were presented using the Kaplan-Meier estimator and analyzed using the Cox proportional hazards model. Simple models were created for all relevant variables (baseline, demographics). Due to the small number of observations, no multiple regression model was created. Two Kaplan-Meier curves were compared using a log-rank test. Hazard ratios (HR) with $95 \%$ confidence intervals $(\mathrm{Cl})$ were presented as a result of the Cox regression. Statistical analyses were performed in JMP 15.2.0 (SAS Institute Inc., Cary, NC, USA, 2020)

\section{Results}

Sixty-one consecutive patients underwent TA-TAVI for native AS. Patients were elderly with median age of 80.0 years (76.00-84.0), $55.7 \%$ were male and $81.0 \%$ had symptoms of heart failure in III/IV class according to the New York Heart Association (NYHA). All patients were considered high risk according to median Logistic EuroSCORE I and STS scores 18.2\% (11.6-27.7) and $4.8 \%$ (3.3-8.2), respectively. The median aortic valve area (AVA) was $0.70 \mathrm{~cm}^{2}(0.60-0.90)$ and the median value of the maximal/mean transaortic gradient was $82.0 \mathrm{~mm} \mathrm{Hg}$ (59.5-93.5)/49.0 (36.0-61.0). Baseline clinical and echocardiographic characteristics are presented in Table I. The procedure success rate was $96.7 \%$. All patients underwent balloon aortic valvuloplasty prior to valve deployment. All patients received only one prosthesis, so no valve-in-valve procedure was necessary. In 1 case a second valve was used due to problems with the delivery 
Table I. Baseline characteristics of patients

\begin{tabular}{|c|c|}
\hline Parameter & Apical access $(n=61)$ \\
\hline Age, median (IQR) [years] & $80.0(76.0 ; 84.0)$ \\
\hline Weight, median (IQR) [kg] & $72.5(60.8 ; 79.5)$ \\
\hline BMI, median (IQR) $\left[\mathrm{kg} / \mathrm{m}^{2}\right]$ & $26.20(24.7 ; 29.0)$ \\
\hline Male, $n(\%)$ & $34(55.7)$ \\
\hline Diabetes mellitus, $n(\%)$ & $27(45.0)$ \\
\hline Atrial fibrillation, $n(\%)$ & $22(36.7)$ \\
\hline Hypertension, $n(\%)$ & $56(93.3)$ \\
\hline CVE, $n(\%)$ & $11(18.0)$ \\
\hline COPD, $n(\%)$ & $12(20.0)$ \\
\hline $\mathrm{PCl}, n(\%)$ & $14(33.3)$ \\
\hline CABG, $n(\%)$ & $17(27.9)$ \\
\hline GFR, mean $\pm \mathrm{SD}[\mathrm{ml} / \mathrm{min}]$ & $54.0 \pm 21.0$ \\
\hline NT pro BNP, median (IQR) [pg/ml] & $1336.0(743.0 ; 8313.5)$ \\
\hline Creatinine, median (IQR) [mmol/I] & $90(76.0 ; 109.0)$ \\
\hline Hemoglobin, mean \pm SD [g/dl] & $11.2 \pm 1.8$ \\
\hline Logistic EuroSCORE, median (IQR) (\%) & $18.2(11.6 ; 27.7)$ \\
\hline EuroSCORE 2, median (IQR) (\%) & $5.3(3.0 ; 9.0)$ \\
\hline STS, median (IQR) (\%) & $4.8(3.3 ; 8.2)$ \\
\hline Ejection fraction, median (IQR) (\%) & $55.0(45.0 ; 64.5)$ \\
\hline AVA, median (IQR) $\left[\mathrm{cm}^{2}\right]$ & $0.70(0.60 ; 0.90)$ \\
\hline AVPG, median (IQR) [mm Hg] & $82.0(59.5 ; 93.5)$ \\
\hline AVMG, median (IQR) [mm Hg] & $49.0(36.0 ; 61.0)$ \\
\hline $\mathrm{RVSP}[\mathrm{mm} \mathrm{Hg}]$ & $42.00(33.0 ; 57.0)$ \\
\hline
\end{tabular}

Data are presented as number and percentage. AVA - aortic valve area, AVMG - aortic valve mean gradient, AVPG - aortic valve peak gradient, $B M I$ - body mass index, $C A B G$ - coronary artery bypass grafting, COPD - chronic obstructive pulmonary disease, CVE - cerebrovascular event - stroke or transient ischemic attack, EuroSCORE - European System for Cardiac Operative Risk Evaluation, GFR - glomerular filtration ratio, IOR - interquartile range, NT pro-BNP - N terminal pro $B$ type natriuretic peptide, $P C I$ - percutaneous coronary intervention, STS - Society of Thoracic Surgeons, RVSP - right ventricular systolic pressure.

system. Conversion to open heart surgery was required in 2 cases, in 1 patient due to a severe paravalvular leak and in the second one due to a problem with apex cannulation. Procedural data and results are presented in Table II. All of the complications are presented in Table III. The remaining procedures were successful, with a good echocardiographic result. Median maximal and mean gradient values were $14.0 \mathrm{~mm} \mathrm{Hg}(10.2-21.0)$ and $8.00 \mathrm{~mm} \mathrm{Hg}$ (5.7-12.0), respectively. We found slightly lower median left ventricle ejection fraction at discharge than admission, $55.0 \%(45.0-64.5)$ vs. $50.0 \%$ (43.560.0), $p=0.007$. In most cases, we found at most only mild regurgitation of bioprosthesis, $90.2 \%$. Periprocedural stroke occurred in 1 case, as did myocardial infarction. Although complications related to apex cannulation did not occur, the bleeding complication rate was $14.8 \%$, while the need of transfusion of packed red blood cells occurred in $39.3 \%$. Major bleeding complications were
Table II. Procedural data

\begin{tabular}{lc} 
Parameter & Rresult \\
\hline Procedure duration, median $(\mathrm{IQR})[\mathrm{min}]$ & $115(95 ; 152.5)$ \\
\hline Radiation dose $[\mathrm{mGy}]$ & $392(228 ; 631.5)$ \\
\hline Contrast agent $[\mathrm{ml}]$ & $150(103.75 ; 200.0)$ \\
\hline \begin{tabular}{l} 
Valve type, $n(\%):$ \\
\hline Balloon expandable
\end{tabular} \\
\hline Self-expandable & $42(68.8)$ \\
\hline AVPG, median $(\mathrm{IQR})[\mathrm{mm} \mathrm{Hg}]$ & $19(31.2)$ \\
\hline AVMG, median (IQR) $[\mathrm{mm} \mathrm{Hg}]$ & $14.0(10.2 ; 21.0)$ \\
\hline Ejection fraction (\%), median (IQR) & $8.0(5.8 ; 12.00)$ \\
\hline PVL, $n(\%):$ & $50.0(43.5 ; 60.0)$ \\
\hline None & $32(52.5)$ \\
\hline Mild & $23(37.7)$ \\
\hline Moderate & $1(1.6)$ \\
\hline Severe & $1(1.6)$
\end{tabular}

AVMG - aortic valve mean gradient, AVPG - aortic valve peak gradient, $I Q R$ - in-terquartile range, $P V L$ - perivalvular leak.

Table III. Major periprocedural complications. Data are presented as number and percentage

\begin{tabular}{lc} 
Complications & $n(\%)$ \\
\hline Valve displacement & 0 \\
\hline Second valve, bailout & $1(1.6)$ \\
\hline AVB requiring PM ${ }^{1}$ & $4(6.6)$ \\
\hline Cardiogenic shock & $4(6.6)$ \\
\hline Conversion to surgery & $2(3.4)$ \\
\hline Cardiac tamponade & $2(3.6)$ \\
\hline VARC 2 bleeding complications & $9(14.8)$ \\
\hline Major & $8(88.9)$ \\
\hline Minor & $1(11.1)$ \\
\hline Acute renal failure & $5(8.2)$ \\
\hline Blood transfusion & $24(39.3)$ \\
\hline Myocardial infarction & $1(1.6)$ \\
\hline Stroke & $1(1.6)$
\end{tabular}

PM- pacemaker, ${ }^{1}$ During in-hospital stay.

mostly associated with a second vascular access for pigtail insertion $(n=3)$. Two cases were associated with prolonged drainage from the index access site. Our registry showed that the need for pacemaker (PM) implantation, during index hospital stay after TAVI, occurred in 6.6\%. Similarly, PM implantation was required in $6.6 \%$ of patients before the procedure, while on the waiting list. Six (9.8\%) patients died during the index hospital stay. Three patients died due to bleeding complications related to gastrointestinal bleeding and retroperitoneal hematoma. In 2 cases septic shock and in one myocardial infarction were causes of 3 subsequent deaths. The 30-day mortality rate was $18.0 \%$, and all-cause mortality at 12 months was $24.6 \%$ (Figure 1). Further analysis revealed factors 


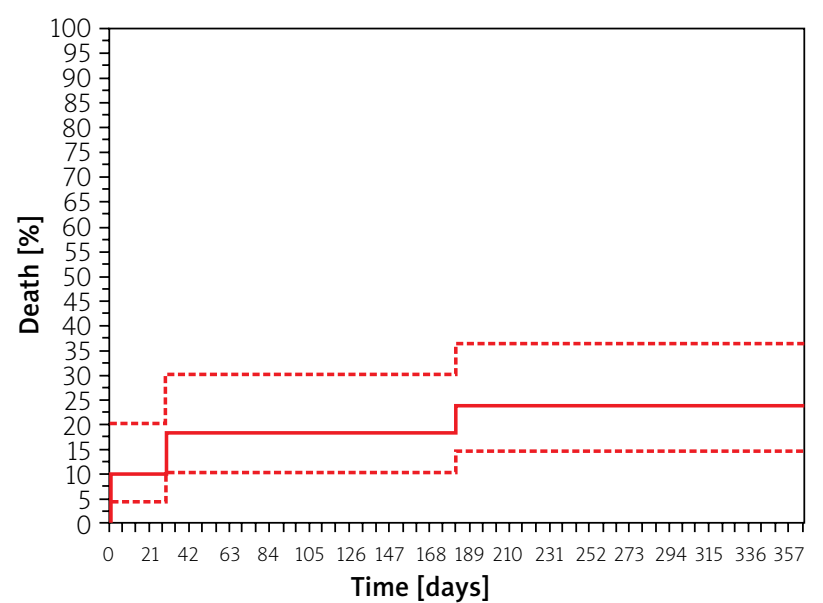

\begin{tabular}{|l|c|c|c|c|}
\hline Total & 0 days & 30 days & 182 days & $\mathbf{3 6 5}$ days \\
\hline At risk & 59 & 51 & 44 & 34 \\
\hline $\begin{array}{l}\text { Cumulative number } \\
\text { of events }\end{array}$ & 0 & 11 & 14 & 15 \\
\hline $\begin{array}{l}\text { Cumulative events } \\
\text { percentage (\%) }\end{array}$ & 0.00 & 18.64 & 23.73 & 25.42 \\
\hline Event probability (\%) & 0.00 & 18.98 & 24.50 & 26.72 \\
\hline
\end{tabular}

Figure 1. Kaplan-Meier curve for cumulative probability of death for entire sample

which had a strong association with 12-month mortality. These were previous CVE (stroke or transient ischemic attack), glomerular filtration rate (GFR), AVA, right ventricular systolic pressure (RVSP) and serum level of N-terminal prohormone of brain natriuretic peptide (NT-proBNP) (RR for CVE 3.17, 95\% confidence interval (CI): 1.15-8.76: $p=0.026$; RR for AVA per $0.1 \mathrm{~cm}^{2} 1.28,95 \% \mathrm{Cl}: 1.03-$ 1.55: $p=0.024$; RR for GFR per $1 \mathrm{ml} / \mathrm{min} 0.96: 95 \% \mathrm{Cl}$ : 0.94-0.99: $p=0.007$; RR for NT-proBNP per $1000 \mathrm{pg} / \mathrm{ml}$ 1.07: $95 \% \mathrm{Cl}: 1.01-1.17: p=0.033$; RR for RVSP per $1 \mathrm{~mm}$ $\mathrm{Hg}$ 1.07: 95\% Cl: 1.02-1.16: $p=0.011$ (Figure 2). Despite no statistical significance ( $p=0.07$ ), the NYHA class assessment at 30 days showed great clinical improvement; $93 \%$ of survivors were in class I or II. This beneficial effect was maintained after 6 months: $97.6 \%$ of patients in class I or II NYHA, $p=0.028$.

\section{Discussion}

Currently, TAVI gives the option for an effective treatment for patients who, according to the Heart Team decision, are not appropriate candidates for surgical aortic valve replacement [5]. While the transfemoral approach gives the best clinical outcomes, it cannot be used in everyone, particularly not in patients with severe iliofemoral atherosclerosis. Atherosclerosis is a systemic disease that included many vascular territories [11]. Peripheral artery disease often coexists with significant carotid artery stenosis [12]. In severe form, such as porcelain aorta, it makes it impossible to even use minimally invasive surgical techniques [13]. In those cases, TA is the

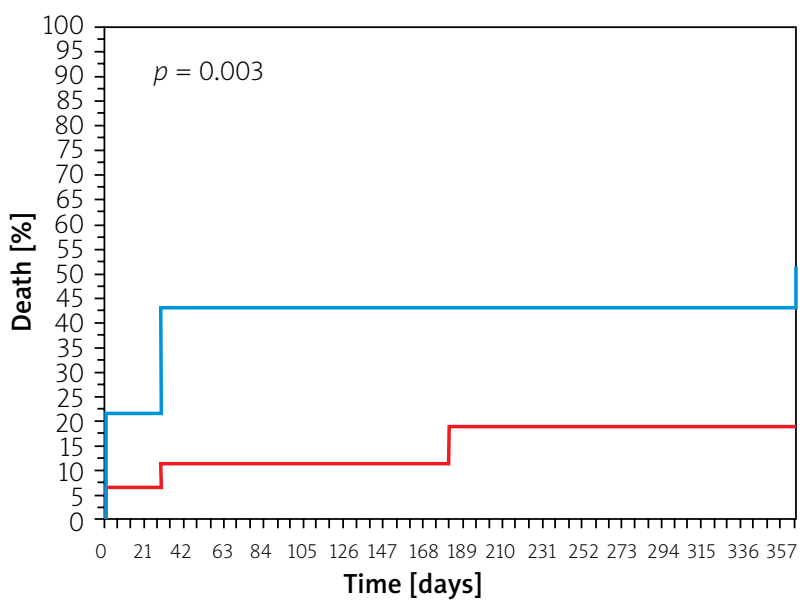

\begin{tabular}{|l|c|c|c|c|}
\cline { 2 - 5 } \multicolumn{1}{c}{} & CVE & \multicolumn{3}{c}{ No CVE } \\
\hline Group: No & 0 days & $\mathbf{3 0}$ days & $\mathbf{1 8 2}$ days & $\mathbf{3 6 5}$ days \\
\hline At risk & 45 & 40 & 36 & 27 \\
\hline $\begin{array}{l}\text { Cumulative number } \\
\text { of events }\end{array}$ & 0 & 5 & 8 & 8 \\
\hline $\begin{array}{l}\text { Cumulative events } \\
\text { percentage (\%) }\end{array}$ & 0.00 & 11.11 & 17.78 & 17.78 \\
\hline Event probability (\%) & 0.00 & 11.33 & 18.72 & 18.72 \\
\hline
\end{tabular}

\begin{tabular}{|l|c|c|c|c|}
\hline Group: yes & 0 days & 30 days & 182 days & 365 days \\
\hline At risk & 14 & 11 & 8 & 7 \\
\hline $\begin{array}{l}\text { Cumulative number } \\
\text { of events }\end{array}$ & 0 & 6 & 6 & 7 \\
\hline $\begin{array}{l}\text { Cumulative events } \\
\text { percentage (\%) }\end{array}$ & 0.00 & 42.86 & 42.86 & 50.00 \\
\hline Event probability (\%) & 0.00 & 42.86 & 42.86 & 51.02 \\
\hline
\end{tabular}

Figure 2. Kaplan-Meier curve for cumulative probability of death by history of previous cerebrovascular event (CVE)

second choice for transcatheter heart valve delivery, but due to its invasive character, bleeding and other complications remain a relevant concern [14]. After starting a TAVI program in our center, the TA route was a predominant access for TAVI, at least during the first year due to factors related to patient characteristics, including extremely high risk patients with multilevel atherosclerosis, and according to CT-scan assessment TF access was not possible in those cases. Our study confirmed that history of CVE, baseline impaired renal function as well as NT-proBNP, RVSP values and AVA may be associated with increased mortality.

In-hospital, 30-day and 12-month mortality rates were $9.8 \%, 18.0 \%$ and $24.6 \%$, respectively. In hospital mortality, compared to estimated surgical risk according to logistic EuroSCORE I Scale $18.2 \%$, was nearly two times lower. In a registry of all-comers with a similar recruitment timeframe, Bagienski et al. observed in-hospital, 30-day, 6-month and 12-month mortality of 6.9\%, 
$10.9 \%, 15.8 \%$ and $17.8 \%$, respectively [15]. The 30-day mortality in the study group was $18 \%$. Some studies show that it can even exceed 20\% [16]. On the other hand, in a study by Walter et al., the authors observed lower 30-day mortality with a survival rate of $91 \%$, but with a similar death rate of $27 \%$ at 12 months of follow-up. In summary, currently available data showed relatively lower 30 -day mortality rate at $12.2 \%$ and only $3.8 \%$ in the PARTNER TA group; 12 -month mortality was $32.2 \%$ and $29.0 \%$, respectively $[5,14]$. The 12 -month all-cause mortality reached $24.6 \%$ but in the present study TA was the only possible method of invasive treatment in the group of patients with many comorbidities. Compared with the group of patients who received conservative treatment in the PARTNER I trial, 12-month mortality in the present study was two times lower (24.6\% vs. 50.7\%) [5].

In our study, bleeding, in the majority of cases life-threatening, was the most common complication, with a $14.8 \%$ frequency, yet complications associated with apex cannulation did not occur. These values are not greater than those available in other registries [17, 18]. Bleeding complication rate may be associated with the fact that the need of anticoagulation in patients with atrial fibrillation (AF) was 36.7\%. TA may also be associated with new onset of AF [19]. Larger registries confirmed the impact of AF on bleeding complications [20]. Presence of AF is not only significant in terms of impact for bleeding complications but is strongly related with further mortality. In the FRANCE-2 registry all-cause mortality at 1 year in patients with pre-existing AF was $25.8 \%$ and was higher in those without AF [19].

The second most common complication was renal failure, with a $8.2 \%$ rate, which was probably associated with surgical trauma and the systemic inflammatory response, as a possible cause of injury $[14,21]$. These results were similar to those previously described [18, 22, 23]. Another serious adverse event that may occur during TAVI is stroke [5].The frequency of periprocedural stroke and myocardial infarction in the study group was at the same level, $1.6 \%$. This low value may be associated with the technical aspect of the procedure performed via the TA approach. The small distance between the sheath inserted through the apex and aortic valve makes positioning and controlled deployment much easier [2]. This fact may also have an impact on further procedure results.

The currently available registries made it possible to create a predictor model of unfavorable outcomes after TAVI. Factors with a significant influence are chronic oxygen therapy, advanced renal failure, atrial fibrillation, poor functional capacity, and decreased baseline cognitive function [24-26]. In our study we found that the history of CVE is strongly related to increased mortality. This fact may be related to TA's more invasive character, which requires general anesthesia and could also cause some rehabilitation problems in the postprocedural peri- od. Importantly, a history of CVE has been considered as a predictor of poor prognosis after cardiac surgery and included in the Society of Thoracic Surgeons (STS) risk score [24]. On the other hand, previous CVEs were not included in the EuroSCORE II risk score model. However, neither of these risk scores were designed for patients scheduled for TAVI [27].

Elevated RVSP is observed quite frequently in patients with AS [28]. Among patients undergoing TAVI, concomitant $\mathrm{PH}$ on echocardiography is found in 20-75\% [29]. Also, in patients undergoing surgical aortic valve replacement for AS, baseline $\mathrm{PH}$ and its severity are associated with mortality, serious complications, and worse late survival [30] Thus, patients with very elevated RVSP are often disqualified from surgical valve replacement due to concerns about high peri-operative morbidity and mortality or doubts about whether or not valve replacement will provide any clinical benefit. Data on the impact of $\mathrm{PH}$ on outcomes after TAVI are less consistent. In the study by Lindman et al. increased RVSP was associated with increased mortality, repeat hospitalizations, and strokes during the first year after TAVI [31]. Barbash et al. reported that the presence of RVSP $>50 \mathrm{~mm} \mathrm{Hg}$ on echocardiography increased the mortality rate immediately after TAVI. In addition, patients with SPAP $>50 \mathrm{~mm} \mathrm{Hg}$ had a prolonged hospitalization at the intensive care unit [32]. Also, another study confirmed a higher mortality rate at 12 months among patients with elevated RVSP [33]. In contrast, in the FRANCE-2 registry, the 30-day outcome did not differ among 2435 TAVI patients with SPAP < 40, 40-60, and $\geq 60 \mathrm{~mm} \mathrm{Hg}$ as assessed by echocardiography [34].

Previous studies have confirmed that elevated levels of NT-proBNP may be associated with worse outcomes $[35,36]$. Koskinas et al. reported that an increased value of NT-pro BNP is associated with a higher risk of all-cause death and cardiovascular death at 2 years and more frequent VARC-2 complications. On the other hand, Ben-Dor et al. did not confirm the significant impact of BNP values on further mortality [37]. Moreover, RVSP and NT-proBNP are not included in risk scores such as the logistic EuroSCORE and STS.

Our study had a relatively small sample size. Data were analyzed retrospectively as a registry from a single center.

\section{Conclusions}

Transapical TAVI in patients who are not feasible for a transfemoral approach gives a good hemodynamic result with significant clinical improvement. History of CVE, impaired renal function, AVA, increased NT-proBNP and RVSP level may be associated with higher mortality at the 12 months follow-up.

\section{Conflict of interest}

The authors declare no conflict of interest. 


\section{References}

1. Baumgartner H, Falk V, Bax JJ, et al. 2017 ESC/EACTS Guidelines for the management of valvular heart disease. Eur Heart J 2017; 38: $2739-86$

2. Parma R, Zembala MO, Dabrowski M, et al. Transcatheter aortic valve implantation. Expert Consensus of the Association of Cardiovascular Interventions of the Polish Cardiac Society and the Polish Society of Cardio-Thoracic Surgeons, approved by the Board of the Polish Cardiac Society and National Consultants in Cardiology and Cardiac Surgery. Kardiol Pol 2017; 75: 937-64.

3. Roberta Pinto SCP. Epidemiology of aortic valve stenosis (AS) and of aortic valve incompetence (Al): is the prevalence of AS/ Al similar in different parts of the world? https://www.escardio.org/Journals/E-Journal-of-Cardiology-Practice/Volume-18/ epidemiology-of-aortic-valve-stenosis-as-and-of-aortic-valve-incompetence-ai. Accessed October 5, 2020.

4. Eveborn GW, Schirmer H, Heggelund G, et al. The evolving epidemiology of valvular aortic stenosis. the Troms $\varnothing$ Study. Heart 2013; 99: 396-400.

5. Leon MB, Smith CR, Mack M, et al. Transcatheter aortic-valve implantation for aortic stenosis in patients who cannot undergo surgery. N Engl J Med 2010; 363: 1597-607.

6. Kleczynski P, Dziewierz A, Bagienski M, et al. Impact of frailty on mortality after transcatheter aortic valve implantation. Am Heart J 2017; 185: 52-8.

7. Overtchouk P, Modine T. Alternate access for TAVI: Stay clear of the chest. Interv Cardiol Rev 2018; 13: 145-50.

8. Nakatsuka D, Tabata M. Transapical approach for transcatheter aortic valve implantation. Ann Cardiothorac Surg 2017; 6: 553-4.

9. Kleczyński P, Zasada W, Bagieński M, et al. Paravalvular leak after transcatheter aortic valve implantation (TAVI): Short-term results. Data from Polish national POL-TAVI registry. Cardiol J 2016; 23: 163-8

10. Kappetein AP, Head SJ, Généreux P, et al. Updated standardized endpoint definitions for transcatheter aortic valve implantation: the Valve Academic Research Consortium-2 consensus document. J Thorac Cardiovasc Surg 2013; 145: 6-23.

11. Razzouk L, Rockman CB, Patel MR, et al. Co-existence of vascular disease in different arterial beds: Peripheral artery disease and carotid artery stenosis - data from Life Line Screening ${ }^{\circledR}$. Atherosclerosis 2015; 241: 687-91.

12. Simons PCG, Algra A, Eikelboom BC, et al. Carotid artery stenosis in patients with peripheral arterial disease: the SMART study. J Vasc Surg 1999; 30: 519-25.

13. Osaka S, Tanaka M. Strategy for porcelain ascending aorta in cardiac surgery. Ann Thorac Cardiovasc Surg 2018; 24: 57-64.

14. Madigan M, Atoui R. Non-transfemoral access sites for transcatheter aortic valve replacement. J Thorac Dis 2018; 10: 4505-15.

15. Bagienski M, Kleczynski P, Dziewierz A, et al. Early- and mid-term outcomes after transcatheter aortic valve implantation. Data from a single-center registry. Adv Interv Cardiol 2016; 12: 122-7.

16. Elhmidi Y, Bleiziffer S, Piazza N, et al. Long-term results after transcatheter aortic valve implantation: what do we know today? Curr Cardiol Rev 2014; 9: 295-8.

17. Schymik G, Würth A, Bramlage $P$, et al. Long-term results of transapical versus transfemoral TAVI in a real world population of 1000 patients with severe symptomatic aortic stenosis. Circ Cardiovasc Interv 2015; 8: 1-10.
18. Van Der Boon RMA, Marcheix B, Tchetche D, et al. Transapical versus transfemoral aortic valve implantation: a multicenter collaborative study. Ann Thorac Surg 2014; 97: 22-8.

19. Chopard R, Teiger E, Meneveau N, et al. Baseline characteristics and prognostic implications of pre-existing and new-onset atrial fibrillation after transcatheter aortic valve implantation: results from the FRANCE-2 Registry. JACC Cardiovasc Interv 2015; 8: 1346-55.

20. Tarantini G, Mojoli M, Windecker S, et al. Prevalence and impact of atrial fibrillation in patients with severe aortic stenosis undergoing transcatheter aortic valve replacement an analysis from the SOURCE XT prospective multicenter registry. JACC Cardiovasc Interv 2016; 9: 937-46.

21. Zacharias M, Mugawar M, Herbison GP, et al. Interventions for protecting renal function in the perioperative period. Cochrane Database Syst Rev 2013; 2013: CD003590.

22. Goebel N, Baumbach H, Ahad S, et al. Transcatheter aortic valve replacement: does kidney function affect outcome? Ann Thorac Surg 2013; 96: 507-12.

23. Thomas M, Schymik G, Walther T, et al. Thirty-day results of the SAPIEN aortic bioprosthesis European outcome (SOURCE) registry: a European registry of transcatheter aortic valve implantation using the edwards SAPIEN valve. Circulation 2010; 122: 62-9.

24. Olszewska-Turek K, Tokarek T, Dziewierz A, et al. Changes in cognitive functions and quality of life in patients after transcatheter aortic valve implantation. Adv Interv Cardiol 2020; 16: 82-8.

25. Arnold SV, Reynolds MR, Lei Y, et al. Predictors of poor outcomes after transcatheter aortic valve replacement results from the PARTNER (Placement of Aortic Transcatheter Valve) trial. Circulation 2014; 129: 2682-90.

26. Grevious SN, Fernandes MF, Annor AK, et al. Prognostic assessment of right ventricular systolic dysfunction on post-transcatheter aortic valve replacement short-term outcomes: systematic review and meta-analysis. J Am Heart Assoc 2020; 9: e014463.

27. Wiktorowicz A, Kleczynski P, Dziewierz A, et al. Impact of pre-procedural cerebrovascular events on clinical outcomes after transcatheter aortic valve implantation in patients with severe aortic stenosis. Curr Pharm Des 2018; 24: 641-6.

28. Lancellotti P, Magne J, Donal E, et al. Determinants and prognostic significance of exercise pulmonary hypertension in asymptomatic severe aortic stenosis. Circulation 2012; 126: 851-9.

29. O'Sullivan CJ, Wenaweser P, Ceylan O, et al. Effect of pulmonary hypertension hemodynamic presentation on clinical outcomes in patients with severe symptomatic aortic valve stenosis undergoing transcatheter aortic valve implantation insights from the new proposed pulmonary hypertension classification. Circ Cardiovasc Interv 2015; 8: e002358.

30. Roselli EE, Abdel Azim A, Houghtaling PL, et al. Pulmonary hypertension is associated with worse early and late outcomes after aortic valve replacement: implications for transcatheter aortic valve replacement. J Thorac Cardiovasc Surg 2012; 144: 1067-74.

31. Lindman BR, Zajarias A, Maniar HS, et al. Risk stratification in patients with pulmonary hypertension undergoing transcatheter aortic valve replacement. Heart 2015; 101: 1656-64.

32. Barbash IM, Escarcega RO, Minha S, et al. Prevalence and impact of pulmonary hypertension on patients with aortic stenosis who underwent transcatheter aortic valve replacement. Am J Cardiol 2015; 115: 1435-42. 
33. Schewel D, Schewel J, Martin J, et al. Impact of transcatheter aortic valve implantation (TAVI) on pulmonary hyper-tension and clinical outcome in patients with severe aortic valvular stenosis. Clin Res Cardiol 2015; 104: 164-74.

34. Luçon A, Oger E, Bedossa M, et al. Prognostic implications of pulmonary hypertension in patients with severe aortic stenosis undergoing transcatheter aortic valve implantation study from the france 2 registry. Circ Cardiovasc Interv 2014; 7: 240-7.

35. Seoudy H, Frank J, Neu M, et al. Periprocedural changes of NT-proBNP are associated with survival after transcatheter aortic valve implantation. J Am Heart Assoc 2019; 8: e010876.

36. Koskinas KC, O’Sullivan CJ, Heg D, et al. Effect of B-type natriuretic peptides on long-term outcomes after transcatheter aortic valve implantation. Am J Cardiol 2015; 116: 1560-5.

37. Ben-Dor I, Minha S, Barbash IM, et al. Correlation of brain natriuretic peptide levels in patients with severe aortic stenosis undergoing operative valve replacement or percutaneous transcatheter intervention with clinical, echocardiographic, and hemodynamic factors and prognosis. Am J Cardiol 2013; 112: 574-9. 